\title{
A IMPORTÂNCIA DA COMPREENSÃO DO PAPEL DA CONSCIENNCIA EM PROJETOS DE RESTAURAÇÃO DE RIOS
}

Edilene de Souza Leite

\begin{abstract}
Mestra em Filosofia, Área: Filosofia da Mente, Epistemologia e Lógica pela UNESP- Marília (2017); Colaboradora do Grupo Acadêmico em Ciências Cognitivas GAEC- UNESP/Marília e do Grupo Interdisciplinar CLE Auto-organização UNICAMP/Campinas e do Projeto de Extensão Filosofia Ecológica - UNESP/Marília. Mestra em Filosofia - Área Subjetividade e Contemporaneidade pela Universidade Estadual de Londrina (2014); Licenciada em Filosofia pela Universidade Estadual de Londrina (2010). E-mail: edilenesz@ hotmail.com
\end{abstract}

\section{RESUMO}

A crise hídrica e a situação dos rios em centros urbanos pedem por soluções rápidas e eficientes, o alto custo dos projetos de restauração de rios inviabiliza em países emergentes ações que favoreçam uma mudança da situação atual. Rios como o Tietê na grande São Paulo são conhecidos pelo seu mal cheiro e poluição desmedida. Apesar de nós dispormos de tecnologias e conhecimentos necessários para intervir em situações como esta e outras relacionadas à problemas ambientais decorrentes do impacto direto ou indireto dos modos de vida humana estamos em uma situação praticamente estagnada, em que alguns grupos isolados se mobilizam marchando contra a maré na tentativa de preservar e restaurar parte do meio ambiente enquanto a maioria das corporações ou mesmo indivíduos seguem sem compreender o impacto global de suas ações e escolhas cotidianas. Neste trabalho abordamos um pouco das técnicas de restauração de rios e destacamos a importância de uma teoria da consciência que resgata a relação de interdependência e co-originação entre seres humanos e ambiente como solução para a crise ecológica que estamos hoje.

PALAVRAS-CHAVE: Restauração de Rios. Problemas Ambientais. Meio Ambiente.

\section{THE IMPORTANCE OF UNDERSTANDING THE FUNCTION OF CONSCIOUSNESS IN RIVER RESTORATION PROJECTS}

*Artigo apresentado inicialmente na Universidade Federal De Santa Catarina Centro De Ciências Biológicas, Departamento De Ecologia e Zoologia na Ecossistemas de Águas Continentais Prof. Nei Kavaguichi Leite. Florianópolis, 03 de julho de 2017. Revisão da Língua Portuguesa por Viviane P. Mioto. 


\begin{abstract}
The water crisis and the situation of rivers in urban centers call for quick and efficient solutions, the high cost of river restoration projects makes it impossible in emerging countries to favor a change in the current situation. Rivers like Tietê in greater São Paulo are known for their bad smell and excessive pollution. Although we have the technologies and know-how to intervene in situations like this and others related to environmental problems arising from the direct or indirect impact of human lifestyles, we are in a practically stagnant situation, where some isolated groups mobilize marching against the tide. in an attempt to preserve and restore part of the environment while most corporations or even individuals continue without understanding the global impact of their daily actions and choices. In this paper we discuss some of the techniques of river restoration and highlight the importance of a theory of consciousness that rescues the relationship of interdependence and co-origination between humans and environment as a solution to the ecological crisis we are today.
\end{abstract}

KEYWORDS: River Restoration. Environmental problems. Environment.

\title{
1 INTRODUÇÃO
}

O processo de restauração de um rio é extremamente complexo e visa restabelecer uma área degradada o mais próximo possível de seu estado natural. Um rio apresenta não apenas o comportamento de um sistema complexo, que inclui relações circulares, de interações e interdependência entre os objetos do sistema, como também pode ser visto como um modelo magno de um sistema aberto. Um sistema aberto é um sistema completamente permeável à energia e a matéria, no caso de um rio a permeabilidade em consequência da ausência de fronteira do ambiente estende-se ao trabalho, a entropia e ao volume do sistema. Apesar da aparente imprevisibilidade uma série de padrões apresentam certa regularidade. A Restauração de um rio é um processo natural que se dá através da auto-organização do sistema, contudo a atividade humana e alguns modelos de sociedade, além de serem fatores de influência direta no processo de degradação, acabam também obstruindo o processo de regeneração espontânea de um rio. A restauração de um rio por ação humana envolve uma série de etapas, incluindo por vezes intervenção química ou mecânica, pode levar muito tempo, geralmente tem elevado custo financeiro e precisa do engajamento público, privado, de profissionais especializados de diversas áreas e da comunidade.

\section{RIOS}

A história do surgimento das grandes civilizações está intimamente relacionada à 
povoação de margens de grandes rios, como o rio Nilo (Egito), Jordão (Israel/Palestina), Tigre e Eufrates (Mesopotâmia), os Indo e Ganges (Índia) e Amarelo e Azul (China). Do ponto de vista organizacional e social se destaca comumente a importância dos rios para o fornecimento de água para consumo humano e animal, além do proporcionamento de solos férteis nas proximidades dos rios, elementos essenciais para as atividades humanas de plantio e pecuária e consequentemente para o crescimento de um agrupamento social.

Um rio é distinguido de outros ecossistemas lênticos principalmente pelo seu fluxo de água. Pode ser caracterizado de várias formas com relação as suas dimensões (longitudinal, lateral, vertical, temporal); regimes (pluvial, glacial, misto); padrões de sinuosidade e curso (curvas, meandros, confluência); nível (planalto; planície); fluxo e escoamento (laminar, turbulento); composição sedimentar (águas claras, pretas, brancas) e ordem (de acordo com número de confluências).

No entanto, três conceitos são fundamentais quando falamos de rios: nascente, bacia hidrográfica e desembocadura.

A nascente, também conhecida como olho-d'água, mina-d'água ou cabeceira se refere ao ponto onde a água subterrânea emerge e passa a fluir no solo de forma resiliente. O fluxo da água é geralmente unidirecional ao longo de um declive, em consequência do efeito exercido pela gravidade. A partir da nascente a rota de dispersão de um rio depende de uma série de variáveis, incluindo o encontro com outras nascentes ou a dispersão por canais laterais.

A bacia hidrográfica é uma definição conceptual de uma região entorno de um rio que atua funcionalmente recolhendo água e abastecendo o rio. As bacias hidrográficas podem ser delimitadas espacialmente a partir da funcionalidade e influência que exercem em um determinado rio e seus tributários, apresentado uma área de atuação horizontal e vertical, tanto positiva quanto negativa. Em outras palavras, as bacias recolhem as águas subterrâneas, de chuvas, montanhas, e coletam as águas da superfície do solo reunindo-as em conjunção com as águas dos riachos tributários para um rio maior, alguns se referem às bacias hidrográficas como áreas de drenagem. As bacias hidrográficas geralmente são ricas em biodiversidade.

Já a desembocadura ou a foz é o ponto onde o rio desagua, geralmente em outro corpo de água, como um rio, mar ou lagoa. A foz pode ser classificada de acordo com seu formato em mista ou em estuário, para formato de funil e delta para formato de leque. $\mathrm{O}$ corpo de um rio é compreendido a partir destes três elementos, o ponto onde começa a nascente, a bacia hidrográfica e a sua foz. 
Em geral a classificação do rio é baseada na hidrogeomorfologia e na qualidade da água para utilização humana. Essa classificação baseada na utilização humana, além de ter a finalidade de prever para quais atividades a água poderá ser utilizada, visa regularizar a dispersão de efluentes nos rios. A salinidade da água, a presença de patógenos e coliformes, a presença de metais e produtos tóxicos ou letais para seres humanos e outros animais baliza esta classificação no Brasil. Entre as atividades humanas se destacam a água destinada: ao consumo humano em uso doméstico (preparo de alimentação, higiene, limpeza); ao uso recreativo (natação, esqui, mergulho); à produção alimentar (aquicultura); para irrigação de hortaliças ou plantas frutíferas e arbóreas; à dessedentação de animais; à navegação e à harmonia paisagista (CONAMA, 1998).

Naturalmente podemos encontrar rios de águas doces, águas salinas e águas salobras, e no mesmo rio podemos ter esses diferentes tipos de águas em diferentes locais. Por exemplo, rios que desembocam no mar têm regiões de sua foz salobra. Essas diferenças nas regiões dos rios criam habitats com características ecológicas diversas que influenciam diretamente na constituição da flora e fauna do rio e suas margens. Algumas espécies da flora e da fauna são utilizadas como bioindicadores, de forma complementar, para avaliar a qualidade da água e a saúde de ecossistemas. Como a diversidade e a abundância das espécies são afetadas pelos impactos das ações humanas, a distribuição espaço-temporal dos organismos pode apontar índices importantes que sugerem se o ambiente está preservado naturalmente, se é um ecossistema alterado ou se sofreu algum impacto, pois quando submetidos a condições adversas estas espécies podem resistir ou morrer. Junto com os bioindicadores a condição de um rio pode indicar uma serie de padrões químicos e físicos.

Enquanto essas características dos rios podem ser mensuradas quantitativamente e qualitativamente por diversas ciências (verificando características como: coloração da água; salinidade; temperatura; oxigênio; odor; turbidez; $\mathrm{pH}$; forma do curso do rio e velocidade do fluxo da água; profundidade; tipos de nutrientes e elementos químicos presentes; espécie de vegetação hidropônicas ou espécies de organismos que vivem nestes ambientes), em algumas civilizações os rios são valorizados e vistos como organismos vivos. Não é estranho os rios aparecerem em registros como espécie de deuses, ou nos contos e narrativas como os próprios pais e mães dos povos, sendo por vezes celebrados em festivais e datas comemorativas. $\mathrm{Na}$ Índia, por exemplo, o Rio Ganges é visto como um rio sagrado e utilizado para rituais.

Partindo do aspecto biológico a água é praticamente um elemento inerente à vida da 
maioria dos seres que habitam o planeta terra. No caso de seres humanos se estima que entre $60 \%$ a $70 \%$ do corpo é composto de água. Alguns rios estão sujeitos às secas, enchentes ou ao congelamento, esses processos não podem ser ignorados pelas comunidades ribeirinhas ou que dependem das águas dos rios, o que cria um laço íntimo e forte entre as comunidades e os rios com os quais elas convivem. Para lidar com as constantes modificações que um rio passa e sua alta dinamicidade é preciso conhecê-lo e desenvolver técnicas, para que possam lidar com situações como as enchentes, para armazenar água durante a seca ou para transportar água e irrigar as plantações. É da consciência dessa relação de dependência, vida-água, que emerge a cultura e o cultivo do respeito, da admiração e do cuidado contínuo dos rios, passado de geração a geração.

A dinamicidade dos rios sempre foi reconhecida e reverenciada. Heráclito de Éfeso, filósofo do século VI e V a.C., observando o dinamismo universal em um dos fragmentos de seu texto comenta "Não se pode descer duas vezes o mesmo rio e não se pode tocar duas vezes uma substância mortal no mesmo estado, pois, por causa da impetuosidade e da velocidade da mudança, ela se dispersa e se reúne, vem e vai. (...) Nós descemos e não descemos o mesmo rio, nós mesmos somos e não somos." (REALE, 1990, p. 36). Esse dinamismo do rio não é apenas uma expressão poética da natureza, mas o próprio pulsar da vida. Para o processo de restauração esse dinamismo é um desafio, sendo muito significativos os registros históricos de um rio para compreender a sua identidade e planejar o que deve ser restaurado, para atender as condições político-sociais de uma comunidade.

Como a existência humana e o processo de ocupação da superfície terrestre sempre esteve relacionada à disposição da água, podemos afirmar que o processo evolutivo não é apenas do rio, mas é também uma representação da própria consciência humana de sua natureza, devido à relação de interdependência entre as atividades dos seres humanos e o seu ambiente. Em geral, compreende-se que as características hidrológicas, químicas e biológicas de ecossistemas aquáticos são definidas pelo clima, a geologia e a cobertura vegetal ao redor desse. Entretanto, as atividades humanas como a agricultura, a pecuária, a exploração mineral, as atividades de produção industrial e o processo de urbanização nos modelos e nas escalas que são desenvolvidos nas sociedades atuais (com exceção de modelos sustentáveis, principalmente tribais e de povos originários) vêm influenciando em diferentes escalas as condições hidrológicas, químicas e biológicas dos rios.

Nos grandes centros urbanos esta influência nos rios é catastrófica. Entre as 
consequências do processo de urbanização e da construção irregular de moradias próximas as margens de rios se destacam: poluição com descarga de esgoto e lixo; diminuição de absorção hídrica do solo; alagamentos e inundações; assoreamento dos rios, destruição da paisagem natural, extinção de peixes e outros organismos aquáticos (PMBISB, 2009). Além disso, podemos observar uma redução na qualidade de vida das comunidades próximas, com o surgimento de doenças provocadas pela poluição da água ou pelo resultado de contaminação, além da presença de odor ruim, impossibilidade de exploração para lazer ou transporte aquático, até mesmo uma alteração na dieta alimentar da comunidade em consequência da extinção de peixes ou animais que bebem água no rio e inclusive um comprometimento da cadeia alimentar em geral.

A degradação de um rio pode ser observada em diferentes escalas e pode afetar várias características e/ou diferentes regiões de um mesmo rio. Entende-se por degradação o processo de alteração adversa das características do meio ambiente. A poluição se refere à degradação da qualidade ambiental resultante de atividades que direta ou indiretamente: a) prejudiquem a saúde, a segurança e o bem-estar da população; b) criem condições adversas às atividades sociais e econômicas; c) afetem desfavoravelmente a biota; d) afetem as condições estéticas ou sanitárias do meio ambiente; e) lancem matérias ou energia em desacordo com os padrões ambientais estabelecidos (PNMA, Lei nº 6938/81).

A degradação de um rio pode ser analisada partindo de dois aspectos: a quantidade de água, ou seja, o fluxo disponível e a qualidade da água. A alteração da qualidade da água geralmente está associada à poluição e a salinidade da água, problema que pode também ser consequência ou estar correlacionado com a redução da quantidade de água fluindo no rio. As causas de degradação de um rio podem ser tanto naturais - em decorrência de chuvas excessivas, alagamentos, períodos de secas, terremotos, tsunamis, furacão - , até mesmo pelo próprio ciclo natural de um rio ou pode ser por ação antrópica (humana).

Entre algumas das ações antrópicas que tem um impacto direto no fluxo dos rios se nota: a construção de barreiras e comportas para captação de água; instalação de hidrelétricas; alteração e interrupção de curso do rio para construção de estradas e rodovias; modificação do fluxo para regulação de reservatório e dragagem comercial de areia. Com a relação à qualidade da água temos os adubos, fertilizantes e agrotóxicos, fezes e urinas de animais em conjunção com lançamento de efluentes nos rios (resíduos indústrias, domésticos e de esgoto), que contribuem com o aumento da concentração de nutrientes nos rios, principalmente fósforo e 
nitrogênio, e consequentemente levam ao processo de eutrofização.

Eutrofização artificial é quando ocorre uma alta produção biológica resultante de aporte de nutrientes ou matéria orgânica. Geralmente há um rápido crescimento de alguns organismos da flora ou fauna. A proliferação de algas é um processo natural, mas pode ocorrer como resultado da ação humana, e a floração dessas leva a alteração da cor e odor da água, e no final de seu ciclo de vida ocorre à liberação de substâncias tóxicas na água, tornando a água imprópria para consumo humano sem o tratamento prévio, levando não só a mortandade de peixes como o aumento de certas bactérias, vírus e outros patógenos (Esteves, 1988 \& Likens, 2004).

As causas de degradação dos rios e o impacto desses processos são muito diversos e vão muito além do que comentado nesse texto. A chuva ácida, o desmatamento, águas fluviais mistas com esgotos e uma série de outros elementos como os acidentes com hidrelétricas e vazamentos de óleos ou mananciais subterrâneos contaminados podem entrar na listados das causas, mas é muito notável a influência reciproca das interações humanas e do ambiente. Assim para o processo de restauração de um rio não existe um protocolo geral que se aplique a todos os casos, cada rio precisa ser tratado a partir das suas condições particulares e de sua identidade.

\section{O PROCESSO DE RESTAURAÇÃO}

Como comentamos na introdução a restauração de um rio é um processo que ocorre através de regeneração espontânea e quando os ciclos naturais não estão sendo interrompidos ou o ecossistema tem as condições necessárias para se restabelecer sem as intervenções humanas ou "artificias".

Os processos do ambiente naturalmente conduzem os rios a mudanças de estados que tendem ao equilíbrio e através da constituição de hábitos há a formação de uma identidade, mas dependendo do estrago pode levar décadas para esse processo acontecer. Devido à crise hídrica e das águas de rios serem uma das fontes de água doce mais importante, restaurar e proteger os rios se tornou uma questão emergencial para alguns países, sendo as intervenções humanas, portanto uma ferramenta fundamental para o gerenciamento das causas de degradação e destruição dos rios, e para o aceleramento desse processo de regeneração espontânea para a reabilitação funcional dos ciclos naturais dos rios.

Atualmente os recursos e tecnologias disponíveis para restauração de rios vão desde Complexitas - Rev. Fil. Tem., Belém, v. 3, n. 2 , p. 3-14, jul./dec. 2018 - ISSN: 2525-4154 
mecanismos e técnicas para intervenção mecânica, química e até biológicos. As tecnológicas auxiliam na intervenção mecânica do fluxo, dos cursos e das margens; as químicas na coleta de resíduos e na filtragem utilizando placas sintéticas ou produtos químicos; e as biológicas utilizando algas, fungos, a fauna e flora em geral.

No Manual de técnicas de restauração de rios, disponível para acesso online do Rivers Restoration Center (UK), as escalas e as técnicas apresentadas variam desde pequena escala de intervenções utilizando mão de obra e equipamentos locais até projetos de engenharia civil de larga escala. Basicamente o processo de restauração pode ser dividido em três etapas principais: design e planejamento, implantação e a manutenção do projeto.

Dependendo das condições do rio, a restauração pode incluir a remoção de lixos e a interrupção de descarga de esgotos, ações que podem ser feitas sem muita imprevisibilidade nos resultados e, portanto relativamente fácies de serem colocadas em práticas e de baixo custo. Entretanto, para projetos maiores, por envolverem questões de saúde e segurança pública a restauração exige muito conhecimento teórico-prático e planejamento. Projetos maiores envolvem profissionais de múltiplas áreas - ecólogos, biólogos, engenheiros, arquitetos, limnólogos - e precisa do engajamento da comunidade para se tornar mais eficiente, além da participação do poder público, privado e de ONGs.

Para maior sucesso no projeto o RRC sugere que se inclua:

- Uma definição clara dos resultados esperados e a serem obtidos para orientar a escolha de quais técnicas e recursos disponíveis serão utilizados;

- Estudo e pesquisa da história do rio, suas características e analise de informações e dados comparando com as condições atuais para determinar qual ponto será restaurado;

- Detalhada avaliação para estudar e investigar a técnica escolhida incluindo estudos socioambientais, falseabilidade da técnica;

- Design estabelecendo a composição, tamanho e localização dos trabalhos físicos e especificação apropriada das implantações e manutenção incluindo detalhamento de fases;

- Manutenção e monitoramento apropriado completar o projeto para garantir o sucesso e a manutenção adaptativa do processo de restauração;

- Especificação de cuidados posteriores com plantas inseridas anotando o tempo de cuidado necessário. (MTRR, 2012/2013). 
Após cada fase do projeto ações são programadas para ajustes da manutenção, com a finalidade de realizarem o afinamento dos resultados obtidos com o planejado. $\mathrm{O}$ monitoramento contínuo visa confirmar se os objetivos foram atingidos, e um ciclo de monitoramento e manutenção é mantido durante o projeto e após completar as ações, para a conservação do rio restaurado.

\section{CONSIDERAÇÕES FINAIS}

O maior desafio atual para o processo de restauração é às vezes associado ao custo dos projetos, e a culpa e responsabilidade da situação lançada ao poder público, mas o principal desafio é a conscientização dos seres humanos da importância da água e da relação intrínseca entre a vida não só humana como de outros seres. A terceirização dos serviços de coleta de água e de esgoto, a falta de fiscalização e vigilância dos próprios consumidores contribuem para parte do problema de descarte irregular de resíduos em regiões urbanas.

Além disso, a noção que a natureza não é separada dos humanos e tão pouco deve ser explorada e domada sem pensar nas consequências orienta as ações diárias de modo diferente. A perspectiva chave para uma alteração significativa dessa situação dos rios é a que os fenômenos de grandes escalas como a degradação e destruição dos rios na maioria dos casos se constituem "bottom-up", ou seja, de baixo para cima.

O ciclo de poluição começa dentro de casa com o uso de produtos de limpeza, inseticidas, esteroides e hormônios reprodutivos (Likens, 2004). Por exemplo, em uma cidade com 400 mil residências, se cada casa usar um litro de desinfetante por mês são 400 mil litros lançados. Diariamente são litros e litros de água com esses componentes sendo dispersos no esgoto ou nas vias fluviais. Parte dos componentes lançados chegam intactos nos rios e posteriormente, mesmo com o tratamento de água, não são removidos, como os hormônios e antibióticos.

Todas as outras ações humanas, como o uso de agrotóxicos e a pecuária só permanecem porque o ciclo está sendo sustentado pelas nossas escolhas diárias, mesmo a instalação de hidrelétricas se faz sob a alegação de uma demanda de consumo, consumo que é muitas vezes inconsciente.

A restauração é um processo de remediação que poderia ser evitado com mais educação ambiental e sensibilização da relação intrínseca nossa com a natureza, o desinteresse 
coletivo é o principal elemento que perpetua a poluição hídrica, ainda que pensemos que toda a responsabilidade se deve as políticas vorazes do capitalismo e do liberalismo, esse modelo se sustenta por nossas próprias escolhas diárias. Não importa quanta tecnologia temos disponível e quantas vezes um rio seja restaurado, se a consciência não nos aborrece, somente as doenças e patologias despertam o olhar para os desequilíbrios causados pelas nossas ações e podem então gerar o interesse para alterar esses comportamentos, modificando nossos meios de existência para modos de realizar essas atividades de maneiras mais sustentáveis ou pensar em soluções mais inteligentes para os impactos de nossas ações.

Para alguns países, como o Brasil, que passa o Rio Amazonas, o maior do mundo, a crise hídrica não é um problema que afeta todas as regiões, e apesar de existirem órgãos e legislações na intenção de preservar a água a existências desses não garantem sua a eficácia. A água já é um problema em regiões como o Nordeste e grandes centros urbanos, como a cidade de São Paulo e a ilha de Florianópolis, em Santa Catarina.

Podemos notar algumas tendências e medidas criativas para proteger os rios e os ecossistemas, ações como tratamento de águas cinza e reaproveitamento de água em pequenas escalas já fazem toda a diferença para o ecossistema em escala macro quando temos vários sujeitos engajados.

Para finalizar, uma forma genial de compreender a identidade de um rio é apresentada no texto O "Admirável Amazonas" uma metáfora do pensamento, em que o autor, Silveira (2014) realiza um paralelo entre o pensamento e o rio. Em suas observações ela comenta da aquisição de hábitos pelos rios, um processo dinâmico em que o rio rompe com a rigidez de seus próprios estados renovando e buscando novas possibilidades e finaliza "Dada a abstração própria de pensar-se a si mesmo, grande é o ganho de refletir sobre o rio com todos os recursos que nos forem disponíveis para, seguindo a tradição heraclítica e a vivência popular, compreendermos nossa própria realidade de seres cujo destino supõe que pela representação aprendamos com o passado e terminemos o futuro.”(Silveira, 2014, p. 356). 


\section{REFERÊNCIAS BIBLIOGRÁFICAS}

Esteves, F.A. Fundamentos de Limnologia. Rio de Janeiro: Editora Interciência/Finep, 1988.

Lampert, W.; Sommer, $U$. Limnoecology: the ecology of lakes and streams. New York: Oxford University Press, p. 382, 1997.

Likens, G.E. In: Wieder, K; Novák, M; Vile, M.A. (eds.). Biogeochemical Investigations of Terrestrial, Freshwater, and Wetland Ecosystems across the Globe. Netherlands: Springer, 2004.

Reale, G.; Antisere, D. História da Filosofia: Antiguidade e Idade Média. v.1. São Paulo: Ed. Paulus, 1990.

Silveira, L. Incursões Semióticas. Coleção CLE. Campinas: UNICAMP, 2014.

Yanner, Bar-Yam. Dynamics of complex systems. Massachutsetts: Addison-Wesley, 1997.

A importância dos rios para as primeiras civilizações. Disponível em:

http://www.historialivre.com/antiga/i mportancia_dos_rios.pdf

Hidrelétricas e Rios. Disponível em: https://www.internationalrivers.org/re sources/8391. Acessado em: Julho, 2017.

Plano Municipal Integrado de Saneamento Básico. Florianópolis, 2009

Bioindicadores. Disponível em: http://labs.icb.ufmg.br/benthos/index _arquivos/Page1631.htm.
Degradação de água. Disponível em: https://www.dlsweb.rmit.edu.au/toolb ox/Indigenous/ecotourismtoolbox/top ic_ei/ei_bi03_read0 4.htm.

Causas de degradação de água por ação antrópica. Disponível em: http://www.marc.org/Environment/W ater-Resources/Missouri-RiverbedDegradation/What-Is- Degradation.

Possíveis rotas de dispersão. https://figshare.com/articles/_Possible _routes_of_dispersion_among_sampli ng_sites_in_the_Up

per_Paran_225_River_floodplain_/12 20174. Acessado: Junho de 2017.

\section{RESOLUÇÕES:}

RESOLUÇÃO CONAMA $\mathrm{N}^{\circ} 20$, de 18 de junho de 1986. Publicado no D.O.U. de 30/07/86. Disponível em: http://www.mma.gov.br/port/conama/ res/res86/res2086.html.

Política Nacional do Meio Ambiente. Lei $n^{\circ}$ 6938/81. Disponível em: http://www.planalto.gov.br/ccivil_03/ leis/L6938.htm. Acessado em: Julho de 2017.

A importância dos rios para as primeiras civilizações. Disponível em:http://www.historialivre.com/anti ga/importancia dos rios.pdf

REALE, G.; ANTISERE, D. História da Filosofia: Antiguidade e Idade Média. v.1. São Paulo: Ed. Paulus, 1990.

Hidrelétricas e Rios. Disponível em: https://www.internationalrivers.org/re sources/8391. Acessado em: Julho, 2017. 
LEITE, E.S. A Importância da Compreensão do Papel da Consciência em Projetos de Restauração de Rios. Complexitas - Rev. Fil. Tem. Belém, v. 3, n. 2, p. 3-14, jul./dec. 2018. Disponível em: http://www.periodicos.ufpa.br/index.php/complexitas/article/view/7307>. Acesso em: 05 de agosto de 2019. 